
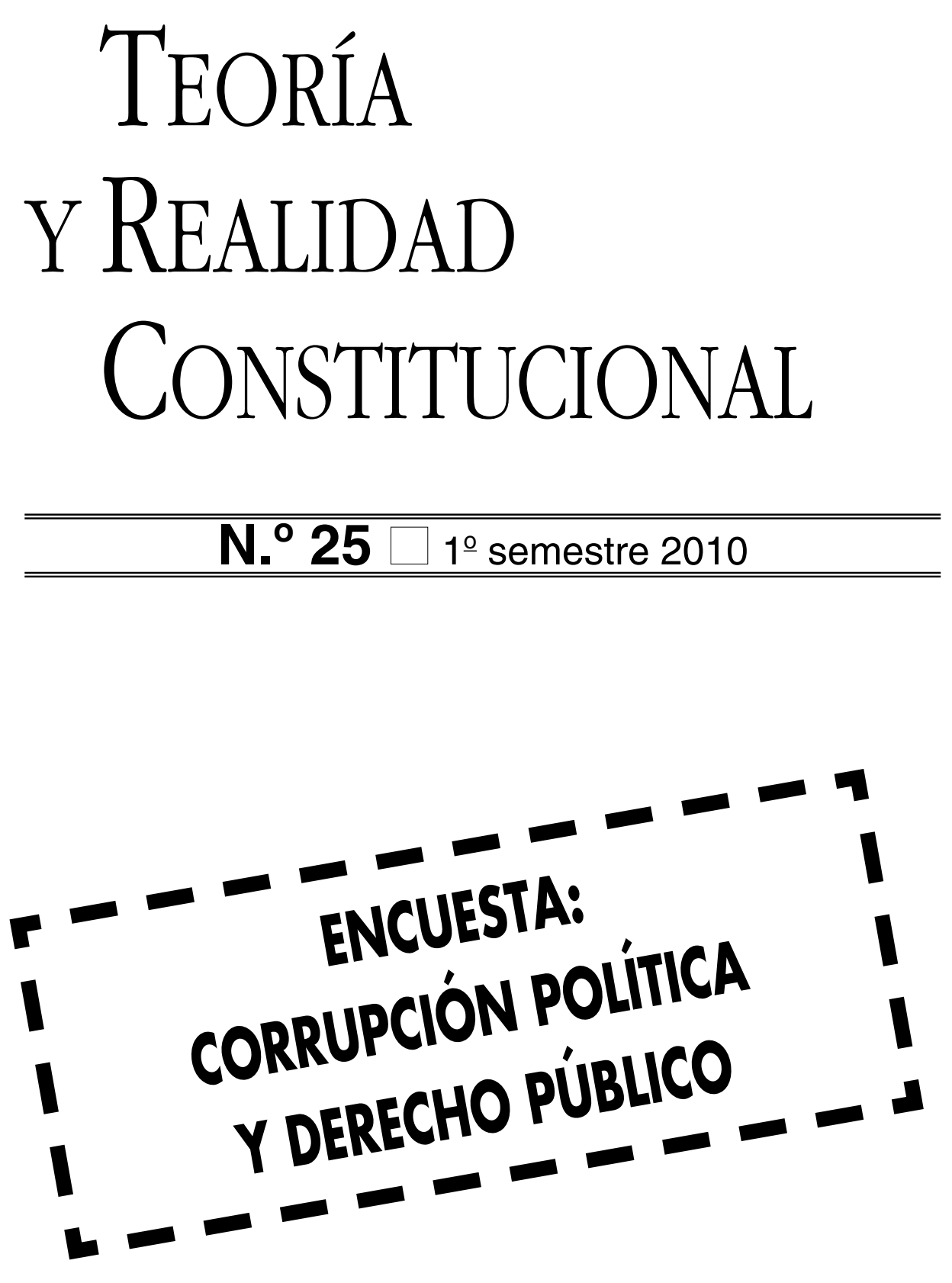


\title{
LA LEY DE PARTIDOS POLÍTICOS Y EL TEST DE CONVENCIONALIDAD EUROPEO. El diálogo entre el Tribunal Constitucional y el Tribunal Europeo de Derechos Humanos en torno a la ilegalización de Herri Batasuna y Batasuna
}

\author{
MERCEDES IGLESIAS BÁREZ \\ Profesora Contratada Doctora de Derecho Constitucional \\ Universidad de Salamanca
}

\begin{abstract}
SUMARIO
I. Introducción.

II. La Ley de Partidos Políticos y el test de convencionalidad.
\end{abstract}

\section{INTRODUCCIÓN}

La Sentencia del Tribunal Europeo de Derechos Humanos Casos Herri Batasuna y Batasuna contra España, de 30 de junio de 2009, avala sin reservas la disolución de los partidos políticos Herri Batasuna y Batasuna, poniendo fin así a un largo proceso judicial que se inició en España hace seis años. Como es de sobra conocido, en aplicación de los arts. 9 y 10 de la Ley Orgánica 6/2002, de Partidos Políticos, la Sala Especial del Tribunal Supremo, mediante la Sentencia de 27 de marzo de 2003, declaró la ilegalización y disolución de los partidos Herri Batasuna, Batasuna y Euskal Herritarrok ${ }^{1}$. En

1 Sobre la Ley Orgánica 6/2002, de Partidos Políticos, de 27 de junio, y su aplicación judicial existe una amplia bibliografía. Vid, entre otras, las monografías de ECHARRI CASI, F Disolución y suspensión judicial de partidos políticos, Ed. Dykinson, Madrid, 2003; TAJADURA TEJADA, J, Partidos políticos y Constitución. Un estudio de la Ley 6/2002, de 27 de junio, y de la STC 48/2003, de 12 de marzo, Civitas, 2004; ESPARZA OROZ, M A, La ilegalización de Batasuna. El nuevo régimen jurídico de los partidos políticos, Aranzadi, 2004; MONTILLA MARTOS, José Antonio (Ed.) La probibición de partidos políticos, Ed. Universidad de Almería, Almería, 2004; ÁLVAREZ CONDE, E, y CATALÀ I BAS, A. El Derecho de Partidos, Colex, 2005; MARTíNEZ CUEVAS, 
la decisión judicial quedó suficientemente probado que los partidos encausados habían incurrido de forma grave y reiterada en un conjunto de actuaciones contrarias a los principios democráticos y los derechos humanos (art. 9 LOPP). Las SSTC 5/2004 y 6/2004, de 16 de enero, desestimaron los recursos de amparo presentados por Batasuna y Herri Batasuna, respectivamente, y consideraron que estas formaciones políticas eran el sustento político de la banda terrorista ETA.

Herri Batasuna y Batasuna, agotada la vía judicial interna, acuden el 19 de julio de 2004 ante el Tribunal Europeo de Derechos Humanos (TEDH), en aplicación del art. 34 del Convenio Europeo de Derechos Humanos (CEDH) ${ }^{2}$, e interponen sendas demandas (núms. 25803/04 y 25817/04) contra el Reino de España ${ }^{3}$. El contenido de las demandas reitera los principales argumentos jurídicos que tanto el Gobierno Vasco había expuesto en el control de constitucionalidad de la LO 6/2002, de Partidos Políticos ${ }^{4}$, como aquellos que arguyeron estas formaciones políticas en su proceso de ilegalización ante el Tribunal Supremo y el Tribunal Constitucional'5 . En este sentido, los demandantes alegan, por una parte, que la disolución partidaria conlleva la lesión de sus derechos a la libertad de expresión y de asociación, reconocidos respectivamente en los arts. 10 y 11 del CEDH. De otro lado, aducen el carácter no accesible y la carencia de la necesaria previsibilidad de la LO 6/2002, de Partidos Políticos, dada su condición de ley ad hoc; la aplicación retroactiva de la Ley de Partidos y la vulneración del principio de proporcionalidad de la medida disolutoria ante la ausencia de un fin legítimo que la justificara así como su carácter innecesario. Finalmente, también alegaron la violación del derecho

M. D.; Régimen jurídico de los partidos políticos, Universidad de Granada, Marcial Pons, Ediciones Jurídicas y Sociales, Madrid, 2006; BAUTISTA PLAZA, D., La función constitucional de los partidos políticos Ed. Comares. Granada, 2006; IGLESIAS BÁREZ M., La ilegalización de partidos políticos en el ordenamiento jurídico español, Comares, 2008; FERREIRO BAAMONDE, X., El proceso de disolución de partidos políticos, Iustel, 2008 y AAVV, La ilegalización de partidos políticos en las democracias occidentales, Dykinson, 2008; y los artículos de MARTÍN DE LA VEGA, A., "Los partidos políticos y la Constitución de 1978. Libertad de creación y organización de los partidos en la Ley Orgánica 6/2002", Revista Jurídica de Castilla y León. Número Extraordinario, Enero 2004; VÍRGALA FORURIA, E., "Comentario a la STS de 27 de marzo de 2003 de ilegalización de Batasuna: El Estado de Derecho penetra en Euskadi", Revista Teoría y Realidad Constitucional, núms. 12-13, segundo semestre 2003-primer semestre 2004 e HINAJEROS PARGA A., "La prohibición de partidos políticos como mecanismo de defensa del Estado", en Revista Teoría y Realidad Constitucional, núms. 10-11, 2002-2003.

2 Artículo 34 del CEDH. Demandas individuales. "El Tribunal podrá conocer de una demanda presentada por cualquier persona física, organización no gubernamental o grupo de particulares que se considere víctima de una violación, por una de las Altas Partes Contratantes, de los derechos reconocidos en el Convenio o sus Protocolos. Las Altas Partes Contratantes se comprometen a no poner traba alguna al ejercicio eficaz de este derecho".

3 Con anterioridad, el 10 de septiembre de 2003, el Gobierno Vasco había interpuesto una demanda ante el TEDH ( $\mathrm{n}^{\circ} 29134 / 03$ ), que fue inadmitida el 3 de febrero de 2004 por incompatibilidad ratione personae.

4 Dio lugar a la STC 48/2003, de 12 de marzo.

5 STS de 27 de marzo de 2003 y SSTC 5 y $6 / 2004$, ambas de 16 de enero. 
a un juicio justo y a un recurso efectivo (arts. 6 y 13 del Convenio) y el derecho a unas elecciones libres (art. 3 del Protocolo $1^{\circ}$ al CEDH).

La Sala del TEDH, en su Decisión de 11 de diciembre de 2007, declaró la admisión parcial de las demandas (rechazó la violación de los arts. 6 y 13 del Convenio y 3 del Protocolo $1^{\circ}$ al CEDH), al tiempo que resolvió acumular las mismas. El 1 de julio de 2008 la Sala notificó a las partes su intención de inhibirse en favor de la Gran Sala, conforme al art. 72. 1 del Reglamento. El Gobierno español se opuso a tal pretensión (art. 72. 2) siendo finalmente, pues, la Sala la que dirimió el litigio. La Sala resuelve, en su Sentencia de 30 de junio de 2009, declarando ajustada al CEDH tanto la Ley de Partidos Políticos española, como su aplicación por los tribunales nacionales. Batasuna presenta un recurso de apelación contra la Sentencia y el 11 de noviembre de 2009 la Gran Sala comunica a las partes implicadas en el proceso que, por decisión unánime de los cinco jueces, ha acordado rechazar el recurso, por lo que en virtud del art. 44.2 del CEDH el Tribunal declara que el fallo judicial es firme desde el 6 de noviembre de 2009.

La decisión de Estrasburgo no deja de ser, en cierta forma, previsible. En el seno del Convenio de Roma la doctrina de la prohibición de partidos políticos construida por el TEDH ha tenido que integrar sistemas jurídicos dispares, como el alemán, que permite la inconstitucionalización de partidos por razones ideológicas, o el español, que no admite la "democracia militante", En materia de disolución de partidos nuestro Derecho constituye, sin duda, una protección mayor que la que dispensa el CEDH y el TEDH al derecho de asociación política, por lo que conforme a la teoría del estándar mínimo el Derecho español es de aplicación preferente en estos supuestos ${ }^{7}$. De ahí que el sentido del fallo judicial europeo fuera anunciado tempranamente por la doctrina española ${ }^{8}$.

6 Sobre el significado y origen de la "democracia militante" vid IGLESIAS BÁREZ M., La ilegalización de partidos políticos en el ordenamiento jurídico español, op. cit., págs. 36 y ss.

$7 \mathrm{El}$ art. 53 del Convenio establece, en este sentido, que "ninguna de las disposiciones del presente Convenio será interpretada en el sentido de limitar o perjudicar aquellos derechos humanos y libertades fundamentales que podrían ser reconocidos conforme a las leyes de cualquier Alta Parte Contratante o en cualquier otro Convenio en el que ésta sea parte". Sobre las consecuencias en términos generales del principio del estándar mínimo del artículo $10.2 \mathrm{CE}$ aplicado al CEDH, Vid. SAIZ ARNÁIZ, A, La apertura constitucional al derecho internacional y europeo de los derechos humanos. El artículo 10.2 de la Constitución, Ed. CGPJ, Madrid, 1999 págs. 223 y ss y RODRÍGUEZ, A, Integración Europea y Derechos Fundamentales, Civitas, 2001, págs. 331 y ss.

8 RODRÍGUEZ, A, en "La declaración de inconstitucionalidad del Partido "Batasuna" y la Convención Europea de Derechos Humanos", en La probibición de partidos políticos, MONTILLA MARTOS, J. A. (Ed.), Ed. Universidad de Almería, Almería, 2004, afirma que la Constitución española establece un estándar mayor de protección pues "la compatibilidad democrática no sólo de los medios utilizados, sino de los fines perseguidos (que sí permite el CEDH), no está presente en la CE», pág. 171. La Ley de Partidos no reconoce tampoco un control ideológico, pues "a pesar de la crítica que pueda merecer el confuso desarrollo de este principio en la LOPP, lo cierto es que el TC ha venido a confirmar que la innovación legislativa que la misma ha traído consigo no ha supuesto cambiar, al menos en este aspecto, el modelo de control de partidos en nuestro país", pág. 172. HERREROS LÓPEZ, J M, "Ilegalización y disolución de partidos políticos", La probibición 
Desde una perspectiva jurídica, pues, la decisión europea no contiene grandes novedades, y puede considerarse, en cierta forma, irrelevante. Es más, la aplicación de la jurisprudencia del TEDH para integrar el canon de constitucionalidad de la Ley de Partidos resulta incorrecta desde el punto de vista de jurídico. No cabe duda de que uno de los problemas fundamentales que presenta la proscripción de actividades antidemocráticas del art. 9 LOPP, al menos en los términos en que el precepto se articula, es el de la proporcionalidad. No hace falta sumergirse en los ingentes repertorios de jurisprudencia constitucional sobre el principio de proporcionalidad para inferir que la redacción del art. 9, en conjunción con el art. 10.2 c) LOPP, consagran un supuesto evidente de desproporcionalidad. Y lo es porque, aisladamente entendidas las conductas, ni se da la necesidad comparativa frente a otras medidas, ni puede negarse que se produce un sacrificio excesivo de los derechos fundamentales afectados. Por ello resulta sorprendente que el TC, a la hora de desechar la desproporcionalidad de la medida de disolución partidaria, se centre en verificar que la Ley supera el test de convencionalidad, que no es aplicable, al menos enteramente, y no se pronuncie sobre el juicio de proporcionalidad español, que sí resulta verdaderamente exigible?

En realidad, lo que hace la STEDH de 30 de junio de 2009 es confirmar su asentada doctrina sobre la prohibición de partidos ${ }^{10}$. Y no podemos dejar de apuntar, por otro lado, que la decisión es un buen ejemplo del diálogo y entendimiento entre el TEDH y nuestro Tribunal Constitucional ${ }^{11}$. Como se verá son continuas las remisiones que el TEDH hace a la interpretación que el TC opera de la Ley de Partidos.

de partidos, MONTILla MARTOS, J. A. (Dir.), Ed. Universidad de Almería, 2004, analiza la jurisprudencia del TEDH sobre todo en el caso del Refah Partisi y otros contra Turquía (pp. 135 y ss) y estima que el TEDH arealiza una interpretación del Convenio y de su artículo 11 en inequívocos términos de democracia militante", pág. 136, por lo que "atendiendo a la jurisprudencia del TEDH, parece vaticinable que un hipotético recurso de BATASUNA ante este Tribunal no obtendría una resolución favorable. Es más, cabe decir que esa jurisprudencia puede considerarse irrelevante para analizar las dudas de constitucionalidad que pudiera presentar la LO 6/2002, y ello porque el Convenio debe interpretarse como un estándar de mínimos, y tanto la Constitución como el Tribunal Constitucional españoles, en el caso que aquí analizamos, establecen un estándar más alto al no exigir un modelo de democracia militante", pág. 151. En el mismo sentido, PORRAS RAMÍREZ, J M, "Comentarios acerca del estatus constitucional de los partidos políticos y de su desarrollo en la Ley Orgánica 6/2002", Revista de las Cortes Generales Madrid, n. 57, 2002, pág. 28

9 Sobre esta crítica y la verificación de que la Ley de Partidos respeta también el principio de proporcionalidad vid IGLESIAS BÁREZ M., La ilegalización de partidos políticos en el ordenamiento jurídico español, op. cit., págs. 192 y ss.

10 Sobre esta cuestión vid principalmente las SSTEDH de 30 de enero de 1998, Partido Comunista Unificado de Turquía contra Turquía; 25 de mayo de 1998, Partido Socialista contra Turquía; 8 de diciembre de 1999, Partido de la Libertad y la Democracia contra Turquía; 9 de abril de 2002, Yazar y otros contra Turquía; 10 de diciembre de 2002, DEP contra Turquía y 31 de julio de 2001 y 13 de febrero de 2003, Partido de la Prosperidad contra Turquía.

11 Sobre esta cuestión vid la interesante obra de QUERALT JIMÉNEZ, A., La interpretación de los derechos: del Tribunal de Estrasburgo al Tribunal Constitucional, Centro de Estudios Políticos y Constitucionales, Madrid, 2008. 
Ahora bien, de lo que no cabe duda es de que el interés de la resolución judicial radica en su valor político. Se trata, de un parte, de una decisión tomada por unanimidad de los jueces. El fallo es, pues, pacífico. Por otro lado, la Sentencia consigue acabar con las sombras de inconstitucionalidad y de falta de adecuación al Convenio que se cernía sobre la Ley de Partidos Políticos. El TEDH ha conseguido zanjar por fin el debate acerca de la legitimidad de la ilegalización de Batasuna ${ }^{12}$.

A continuación, analizaremos los razonamientos jurídicos que llevan al TEDH a concluir que tanto la Ley 6/2002, de Partidos Políticos, como la aplicación que de esta normativa operan el Tribunal Supremo y el Tribunal Constitucional españoles se ajustan a las disposiciones del Convenio de Roma. La STEDH de 30 de junio de 2009 estudia las violaciones alegadas de la libertad de asociación política y la libertad de expresión, si bien toda su fundamentación jurídica se centra en el examen de la vulneración de la libertad de asociación, cuyas conclusiones traslada automáticamente a la alegación de la lesión de la libertad de expresión.

\section{LA LEY DE PARTIDOS POLÍTICOS Y EL TEST DE CONVENCIONALIDAD: ACERCA DE LA VULNERACIÓN DE LA LIBERTAD DE ASOCIACIÓN DEL ART. 11 DEL CEDH -Y DE LA LIBERTAD DE EXPRESIÓN DEL ART. 10 DEL CEDH- EN LA DISOLUCIÓN DE HERRI BATASUNA Y BATASUNA (STEDH DE 30 DE JUNIO DE 2009)}

Herri Batasuna y Batasuna alegan que su disolución constituye una violación de la libertad de asociación que garantiza el art. 11 del CEDH en los siguientes términos: " 1 . Toda persona tiene derecho a la libertad de asociación... 2. El ejercicio de estos derechos no podrá ser objeto de otras restricciones que aquellas que previstas por la ley constituyan medidas necesarias en una sociedad democrática para la seguridad nacional, la seguridad pública, la defensa del orden y la prevención del delito, la protección de la salud o de la moral, o la protección de los derechos y libertades ajenos " ${ }^{13}$. En concreto,

12 TAJADURA TEJADA, J expresa esta idea en su artículo "Batasuna y Estrasburgo" en El Correo de 3 de julio de 2009: "Hasta hoy, algunos apelaban a Europa y al Tribunal Europeo para sostener la disparatada tesis de que nuestra democracia era de baja calidad e incompatible con los estándares europeos. Con estas sentencias, el Tribunal Europeo respalda y convalida nuestra legislación de partidos y la aplicación de la misma por el Tribunal Supremo y por el Tribunal Constitucional. De esta forma, legitimando la actuación del Estado en defensa de la democracia, contribuye a la deslegitimación ETA-Batasuna (y marcas afines) en el ámbito europeo e internacional.

13 Vid BERGER, V, Jurisprudente de la Cour Européenne des Droits de l'Home, 10 ed., Sirey, París, 2007, págs. 617-639, donde existe un buen estudio jurisprudencial del derecho de asociación. 
los demandantes estiman que la Ley 6/2002, de Partidos Políticos carece de la suficiente accesibilidad y previsibilidad; que la Ley se ha aplicado por los tribunales españoles retroactivamente y que se trata también de una ley singular, que carece de un fin legítimo, pues su objeto es el de eliminar el debate político en el País Vasco. Finalmente, entienden que la medida de la disolución de un partido es innecesaria en una sociedad democrática, por lo que, en definitiva, vulnera asimismo el principio de proporcionalidad.

El TEDH, a la hora de resolver los Casos, parte de la premisa de que la disolución de un partido político constituye, sin duda, una injerencia en la libertad de asociación del partido político ${ }^{14}$. Supone, en definitiva, una grave limitación del derecho de asociación política. Ahora bien, la decisión judicial lo que debe dilucidar es si esta intromisión está justificada. En realidad, lo que hace el Tribunal es partir de la idea de que la injerencia es contraria al art. 11 del CEDH, salvo que se cumplan al tiempo tres condiciones: a) que la medida limitativa esté prevista en la ley, b) que se dirija a alcanzar alguno o algunos de los fines legítimos previstos en el art. 11.2 del CEDH, y, finalmente, c) que la medida sea "necesaria en una sociedad democrática" para alcanzar dichos fines.

Por ello, a continuación, el Tribunal examina si la Ley y la ilegalización de Herri Batasuna y Batasuna se adecuan a esta triple exigencia.

\section{II.1. PReVisión EN LA LEY}

El primer requisito, la previsión en la ley de la medida limitadora del derecho, no sólo es una exigencia del test de convencionalidad, sino que también responde a la necesidad de dar cumplimiento a los principios de legalidad y seguridad jurídica, que deben presidir cualquier procedimiento restrictivo de derechos ${ }^{15}$.

14 STEDH de 30 de junio de 2009, Casos Herri Batasuna y Batasuna, par. 52.

15 Sobre los problemas de constitucionalidad que plantea la Ley de Partidos en materia del cumplimiento de los principios de legalidad y seguridad jurídica vid IGLESIAS BÁREZ M., La ilegalización de partidos políticos en el ordenamiento jurídico español, op cit, págs. 165 y ss. El Tribunal Constitucional niega que la Ley incurra en un vicio de inconstitucionalidad por infringir el principio de seguridad jurídica reconocido en el art. $9.3 \mathrm{CE}$. Entre los pilares que apuntalan la fundamentación de su rechazo se hallaría, en primer término, reconocer que la legislación antiterrorista (sic) por razones de eficacia conlleva indefectiblemente la formulación de los supuestos legales en términos generales y abiertos. Así, el Tribunal puntualiza, remitiéndose a la STC 136/1999, de 20 de julio, que "la causa de que ciertamente los supuestos recogidos en el art. 9 de la ley no disfruten del grado de concreción que resultaría de haberlos delimitado con términos puramente descriptivos, es que responden a una constante en lo que al derecho comparado se refiere en materia de legislación antiterrorista que requiere "la previsión de un tipo muy poco específico de colaboración o apoyo a grupos terroristas, condicionado por la necesidad de no dejar fuera, dentro de lo posible, ninguna forma o variedad de respaldo individual o social al fenómeno terroristam. Obviamente, continúa el Tribunal, "la tutela frente al terrorismo comporta un coste en la determinación de la conducta; ahora bien, en este caso, "ese coste no nos aboca a una situación en la que resulte imprevisible para los partidos calcular las consecuencias jurídicas de su conductaw. STC 48/2003, FJ 11. 
La primera duda que este requerimiento plantea es la de determinar qué debe entenderse por "ley", en los términos del art. 11 del CEDH. El concepto de ley que maneja el TEDH es muy amplio, pues no cabe duda de que el mismo debe integrar las diferentes tradiciones jurídicas que acoge el Convenio. En este sentido, "ley" se identificaría con el "Derecho en vigor en un sistema jurídico determinado", e incluiría no sólo leyes en sentido formal sino también leyes en su acepción material, con lo que alcanza tanto al Derecho escrito como a otras fuentes jurídicas: la costumbre y las decisiones jurisprudenciales ${ }^{16}$.

Ahora bien, junto a esta acepción formal de ley, el TEDH exige que la ley limitadora tenga "cualidad material" de ley, es decir, que la norma debe responder a las garantías jurídicas de previsibilidad, publicidad y accesibilidad ${ }^{17}$. El criterio de accesibilidad supone que la ley sea susceptible de ser conocida como norma aplicable al caso, es decir, requiere que "el ciudadano tiene que disponer de informaciones suficientes, dadas las circunstancias, sobre las normas jurídicas aplicables a un determinado caso" ${ }^{18}$, para lo cual se exige también la publicidad con respecto a sus destinatarios ${ }^{19}$.

El Tribunal es consciente del alcance limitado de esta exigencia, ya que no es posible lograr una certeza absoluta en la redacción de las leyes ${ }^{20}$; no obstante, entiende que sí resulta exigible un cierto grado de previsión. El criterio de la previsibilidad demanda, pues, que la limitación se encuentre formulada con la suficiente precisión como para permitir a sus destinatarios vaticinar, dentro de lo razonable, las consecuencias de su actuación. Es decir, una ley será previsible cuando se trate de unna norma expresada con la precisión suficiente para que el ciudadano pueda acomodar a ella su con-

16 CATALÀ I BAS, A. H. «Libertad de expresión e información: la jurisprudencia del TEDH y su recepción por el Tribunal Constitucional: hacia un derecho europeo de los derechos humanos". Revista General de Derecho, Valencia, 2001 págs. 282 y ss. ÁLVAREZ CONDE, E y CATALÀ I BAS, A, "La aplicación de la ley Orgánica de Partidos Políticos. Crónica inacabada de la ilegalización de Herri Batasuna, Batasuna y Euskal Herritarrok", en Foro, Nueva Época, núm. 00/2004, pág. 27.

17 GARCÍA SAN JOSÉ, D. I. Los derechos y libertades fundamentales en la sociedad europea del siglo XXI: análisis de la interpretación y aplicación por el Tribunal Europeo de Derechos Humanos de la cláusula necesaria en una sociedad democrática, Ed. Secretariado de Publicaciones, Universidad de Servilla, Sevilla, 2001, "el sentido de los términos de conformidad con la ley y prescrito por la ley, en los párrafos segundos de los artículos 8 a 11 es idéntico: en ambos casos ha de tratarse de una ley en el sentido del Convenio. La ley es, así, una noción autónoma que no reenvía directamente a la forma con la que una norma puede estar revestida, sino a una cierta "calidad" que debe estar asegurada. Una ley 'en el sentido del Convenio' como ha señalado el Tribunal, es aquella que satisface el triple requisito de previsibilidad, publicidad y accesibilidad", págs. 21 y 22. Vid también una abundante jurisprudencia donde se desarrolla esta exigencia: Caso Sunday Times c. Reino Unido, Sentencia de 26 de abril de 1979, par. 49, Caso Camenzind c. Suiza, Sentencia de 16 de diciembre de 1997, par. 45, y Caso McLead c. Reino Unido, Sentencia de 23 de septiembre de 1998, par. 41.

18 STEDH de 26 de abril de 1979 (Caso Sunday Times c/ Reino Unido), par. 49; STEDH de 27 de octubre de 1983 (Caso Malone) par. 66.

19 STEDH de 25 de marzo de 1983 (Caso Silver y otros) pars. 87 y 26.

20 Vid Caso Ezelin c. Francia, 26 de abril de 1991, par. 45. 
ducta ${ }^{21}$ y cuando el ciudadano pueda ser capaz de "prever razonablemente, según sean las circunstancias, las consecuencias que pueda ocasionar una acción determinada ${ }^{22}$.

Como puede fácilmente observarse el TEDH no se muestra excesivamente riguroso con el cumplimiento de este requisito ${ }^{23}$, y por ello buena parte de nuestra doctrina no tenía dudas acerca de que el supuesto español se ajustaba sin problemas al canon europeo, ya que la Ley de Partidos prevé con las condiciones suficientes de certeza, claridad y accesibilidad tanto las causas de ilegalización de partidos (art. 9) como la medida disolutoria (art. 10) ${ }^{24}$. Y en este mismo sentido se ha pronunciado el TEDH al entender que "la Ley española no sólo estaba en vigor sino que aludía de forma suficientemente precisa a la organización y funcionamiento de los partidos políticos, así como a los comportamientos capaces de provocar su disolución o suspensión judicial (Capítulo III de la Ley),25.

También en este apartado el TEDH resuelve la problemática cuestión de la aplicación retroactiva de la Ley española. Herri Batasuna insiste en que este partido se había autodisuelto antes de la entrada en vigor de la Ley de Partidos y que, por tanto, no puede haber incurrido en los comportamientos prohibidos del art. 9 de la Ley. El Tribunal decide asimismo la desestimación de esta alegación. En primer término, Estrasburgo admite la teoría del Tribunal Supremo español de la "sucesión operativa" entre las formaciones políticas disueltas $^{26}$, por lo que las actuaciones y comportamientos que se achacan a $B a$ tasuna se habrían cometido también por Herri Batasuna.

21 STEDH de 25 de marzo de 1983 (Caso Silver y otros) par. 88. Vid también el Caso Sunday Times c. Reino Unido, de 26 de abril de 1991, par. 45).

22 STEDH de 27 de octubre de 1983 (Caso Malone) par. 66, STEDH de 24 de mayo de 1988 (Caso Müller y otros), par. 29, STEDH de 29 de octubre de 1992 (Caso Open Door y Dublín Well Woman) pars. 59-60.

23 BRAGE CAMAZANO, J. "Aproximación a una teoría general de los derechos fundamentales en el Convenio Europeo de Derechos Humanos", Revista Española de Derecho Constitucional, $\mathrm{N}^{\circ} 74$, mayo-agosto (2005) págs. 128 a 131. Y del mismo autor "Ensayo de una teoría general sustantiva de los derechos fundamentales en el Convenio Europeo de Derechos Humanos", en Integración europea a través de los derechos fundamentales: de un sistema binario a otro integrado, GARCÍA ROCA, J Y FERNÁNDEZ SÁNCHEZ, P.A. (coords), Centro de Estudios Políticos y Constitucionales, 2009, págs. 134 y ss.

Vid STEDH Caso Silver y otros c. Reino Unido, 25 de marzo de 1983; 25 de agosto de 1998, Caso Hertel; 25 de noviembre de 1996, Caso Wingrove; o 13 de julio de 1995, Caso Miloslavsky). Específicamente para el derecho de asociación vid STEDH de 20 de mayo de 1999 Caso Rekvenyi contra Hungría, par. 60 y STEDH de 26 de abril de 1979 (caso Sunday Times), par. 49.

24 SAIZ ARNÁIZ, A, "La disolución de partidos políticos y el derecho de asociación: el test de convencionalidad (art. 11 CEDH)", op cit, pág. 4. RODRÍGUEZ, A, "La declaración de inconstitucionalidad del partido...", op cit pág. 167. ÁLVAREZ CONDE, E. y CATALÁ i BAS, A H. "La aplicación de la ley Orgánica de Partidos Políticos. Crónica inacabada de la ilegalización de Herri Batasuna, Batasuna y Euskal Herritarrok", op. cit., págs. 29 y 30.

25 STEDH de 30 de junio de 2009, Casos Herri Batasuna y Batasuna, par. 57.

26 En la STEDH de 30 de junio de 2009 (par. 58) se alude a los razonamientos de la Sala Especial del TS referentes a la sucesión operativa entre las tres formaciones políticas, su sometimiento a la estrategia marcada por ETA y a todo el elemento probatorio de conductas realizadas 
Además, continúa el Tribunal, la prohibición de retroactividad que garantiza el artículo 7.1 del CEDH sólo se dispone para los procesos penales y el proceso judicial por el que se decide la ilegalización de partidos no es un proceso penal ${ }^{27}$. El Tribunal de Estrasburgo asume, pues, el control extrapenal de los partidos políticos, en línea con el Tribunal Constitucional español ${ }^{28}$. Si bien la creación de un partido tiene su base en el ejercicio del derecho de asociación dimanante del art. $22 \mathrm{CE}$, que los convierte de entrada en entes privados de base asociativa, no es posible calificarlo de un simple ejercicio de este derecho, dado que los partidos "forman parte esencial de la arquitectura constitucional, realizan funciones de una importancia constitucional primaria y disponen de una segunda naturaleza que la doctrina suele resumir con referencias reiteradas a su relevancia constitucional y a la garantía institucional de los mismos por parte de la Constitución ${ }^{29}$. Son "instituciones jurídico-políticas" de gran relevancia y esta consideración fundamenta la constitucionalidad de un régimen jurídico que coincide en parte con el de las asociaciones pero no en todo, es decir, fundamenta la existencia de un estatuto jurídico propio, desgajado del general ${ }^{30}$. Se debe entender, pues, que es legislativamente posible traducir el respeto a la Constitución y a la ley del art. $6 \mathrm{CE}$, en un respeto no ideológico sino "formal", en una obligación para los partidos, al menos en una obligación negativa de no cerrar con su actividad el proceso político democrático como proceso abierto. El apoyo político a la violencia y el terrorismo o la vulneración de la dignidad humana y los derechos que prevé el art. 10.1 CE conducen directamente a obstruir este juego político que, por otra parte, es la base de su reconocimiento constitucional. El pluralismo político es un valor superior del ordenamiento jurídico, al tiempo que un principio de organización del Estado que los partidos "expresan", por lo que parece lógico, por tanto, que al menos les sea exigible que las actividades que

por los partidos con posterioridad a la entrada en vigor de la LO 6/2002, que pueden ser incluidas dentro de los comportamientos prohibidos del artículo 9 LOPP. En este sentido, el FJ 6 de la STS de 27 de marzo de 2003 concluye que "En definitiva, todos estos aspectos de esencial coincidencia entre los tres partidos políticos demandados entre sí y de todos ellos, a su vez, con ETA, ponen de manifiesto una identidad sustancial entre las tres formaciones en los ámbitos mencionados (personal, de fines, de estrategias y de actividad), y, asimismo, un riguroso control de todos ellos por la citada banda criminal. Por esta razón podemos concluir afirmando la existencia en el presente caso de un único sujeto real, que es la organización terrorista ETA, que se oculta tras esa apariencia de diversidad de personalidades jurídicas creadas en diferentes momentos en virtud de una "sucesión operativa" previamente diseñada por aquélla".

27 STEDH de 30 de junio de 2009, Casos Herri Batasuna y Batasuna, par. 59.

28 Sobre la naturaleza extrapenal del proceso judicial de la ilegalización de partidos se pronuncia el TC en la STC 48/2003, FJ 6.

29 Informe del CGPJ sobre el Anteproyecto de Ley Orgánica de Partidos políticos, de 15 de abril de 2002.

30 «Su cualificación funcional no desvirtúa la naturaleza asociativa que está en la base de los partidos, pero eleva sobre ella una realidad institucional diversa y autónoma que, en tanto que instrumento para la participación política en los procesos de conformación de la voluntad del Estado, justifica la existencia de un régimen normativo también propio, habida cuenta de la especificidad de esas funciones". STC 48/2003, FJ 6. 
realicen en desarrollo de sus funciones constitucionales las lleven a cabo sin agredir directamente a este valor. De otro modo no se entiende siquiera cómo pueden desarrollar sus funciones constitucionales. En definitiva, el estatuto del partido depende de que "mantenga su función constitucional" ya que como determina el Tribunal Constitucional «la libertad característica de las asociaciones, y de la que los partidos también disfrutan, no puede ser para éstos tan omnímoda que a su amparo se desvirtúen como instrumentos para la consecución de sus fines constitucionales", por tanto, están sometidos a límites extrapenales que no sólo se refieren a su estructura y funcionamientos internos, "sino también y como cuestión previa, el de respetar los cometidos que ese precepto (art. $6 \mathrm{CE}$ ) enumera como definidores de la condición de partido político ${ }^{31}$.

Por último, concluye el TEDH, los hechos que son tenidos en cuenta por los tribunales españoles son hechos posteriores a la entrada en vigor de la Ley, pero es que además ninguna disposición del CEDH excluye la posibilidad de basarse en hechos anteriores a la promulgación de la ley ${ }^{32}$.

La medida de disolución del partido cumplía, en definitiva, con la condición de estar "prevista en la ley,"33.

\section{II.2. Fin LEGÍTIMO}

El TEDH exige también la legitimidad del fin perseguido con la medida disolutoria. Se trataría de un requisito material, de justificación teleológica. El apartado 2 in fine del art. 11 CEDH prevé expresamente los fines que limitan el ejercicio del derecho de asociación política: «la seguridad nacional, la seguridad pública, la defensa del orden y la prevención del delito, la protección de la salud o de la moral, o la protección de los derechos y libertades ajenos".

Igualmente, en este caso, la doctrina nos advierte del "criterio lato con el que el Tribunal enjuicia la finalidad que justifica la disolución del partido, ${ }^{34}$,

31 STC 48/2003, FJ 6. En el mismo sentido se pronuncia la STC 5/2004 dictada por el Tribunal Constitucional en el recurso de amparo interpuesto por Batasuna contra la STS de 27 de marzo de 2003 que declaraba su ilegalización y disolución, FJ 9.

32 STEDH de 30 de junio de 2009, Casos Herri Batasuna y Batasuna, par. 59.

33 STEDH de 30 de junio de 2009, Casos Herri Batasuna y Batasuna, par. 60.

34 BRAGE CAMAZANO, J.; "Aproximación a una teoría general de los derechos fundamentales en el Convenio Europeo de Derechos Humanos", Revista Española de Derecho Constitucional, núm. 74, mayo-agosto (2005), quien afirma que "como se verá, esta fase de examen no tiene gran relevancia dada la generalidad de las finalidades previstas expresamente por el Convenio con relación a varios derechos o las alegadas con respecto a los demás, y dada también su relativa intercambiabilidad con frecuencia, aparte ya del margen de apreciación que se deja a los Estados", pág. 131. GARCIA SAN JOSE, D.I.; Los derechos y libertades fundamentales en la sociedad europea del siglo XXI, op cit también afirma que "suele ser fácil para los Estados convencer al Tribunal de que la finalidad que motivó su injerencia en el ejercicio del derecho o libertad se corresponde con alguno de los previstos en el párrafo segundo del artículo en el que aparece enunciado dicho derecho o libertad. De hecho, los Estados han sido siempre capaces de persuadir al 
siendo muchas las ocasiones en que el Tribunal despacha esta condición de forma rápida y poco motivada. El elenco del art. 11.2 CEDH es muy amplio y poco preciso por lo que en España ya se anunciaba que no sería complicado que la norma española superara este requisito ${ }^{35}$.

El Tribunal niega la alegación de Herri Batasuna y Batasuna de que su disolución atienda al fin ilegítimo de acabar con la llamada "izquierda abertzale". El mar de fondo de esta conclusión tiene una consecuencia directa sobre dos cuestiones de gran trascendencia: la condición de ley de caso único de la Ley de Partidos Políticos y la consideración del caso español como un supuesto de "democracia militante".

El reproche acerca de la singularidad de la ley deja al descubierto una de las paradojas de la ley: a pesar de que se presenta como una ley reguladora del régimen jurídico de los partidos políticos, en realidad, tal y como advierte BASTIDA "no regula el ejercicio normal del derecho a crear partidos... (si no que se) concibe como una ley que regula las patologías del ejercicio del derecho de partidos... más exactamente, una determinada patología que se quiere eliminar ${ }^{36}$. No se puede negar que el legislador tenía muy presente el referente de Batasuna cuando redactó el art. 9 LOPP; ahora bien, "la Ley impugnada no sólo es general formalmente por el modo en que se halla formulada; sino que también lo es materialmente, en tanto contempla, en abstracto, una serie de conductas cuya realización en forma "reiterada y grave" podría determinar la disolución de cualquier partido presente o futuro, ${ }^{37}$. Se confunde aquí la ocasión que da motivo a que se impulse la aprobación de una ley, que no es más que la lucha contra los partidos que apoyan y legitiman la violencia y el terrorismo, con el objeto de la ley aprobada, que es la regulación, en el caso, de los límites de la libertad externa partidaria ${ }^{38}$. El art.

Tribunal de que en su actuación les guiaba alguno de tales fines legítimos. Esto es así, en parte, debido al hecho de que aun cuando los fines legítimos están enunciados con carácter exhaustivo, su tenor es muy amplio: protección del orden público, los intereses de la seguridad nacional, etc. Y en parte, dado que los órganos de Estrasburgo reenvían al Derecho interno permitiendo que sean las propias autoridades nacionales las encargadas de concretar el contenido vago e indeterminado de tales objetivos, conforme a las concepciones políticas y sociales presentes en sus ordenamientos jurídicos", págs. 22 y 23.

35 SAIZ ARNÁIZ, A, "La disolución de partidos políticos...”, op cit pág. 4. ÁLVAREZ CONDE, E y CATALÀ i BAS, A, “La aplicación de la ley Orgánica de...”, op cit. pág. 30, RODRíGUEZ, Á., "La declaración de inconstitucionalidad del partido...", op. cit., pág. 168.

36 BASTIDA FREIJEDO, F, Informe al Borrador de la Ley Orgánica de Partidos Políticos, www.constitution.rediris.com.

37 FJ 14 de la STC $48 / 2003$.

38 En palabras del Tribunal Constitucional español, «la percepción por el legislador orgánico de que una formación política determinada puede ser contraria, en su actividad y con sus comportamientos, al modelo de partido que tiene encaje y cobertura en la Constitución puede perfectamente erigirse en occasio para la adopción de una ley como la recurrida, pero lo que determinará su constitucionalidad o inconstitucionalidad no será el acierto de esa percepción circunstancial, sino el alcance objetivo de la ley finalmente adoptada, cuya ratio no se limita a reflejar las inquietudes de la ocasión, sino que se acomoda a la racionalidad objetivada del ordenamiento constitucional». STC 48/2003, FJ 14. 
9 LOPP así entendido no es que establezca diferenciaciones injustificadas, irrazonables o arbitrarias, es que no diferencia entre los destinatarios de la norma. No implica, pues, que la ley sea autoaplicativa, con intromisión en la labor de los jueces y tribunales y no supone una merma de la tutela judicial efectiva en la que Herri Batasuna y Batasuna no dispongan de vías judiciales para hacer frente al acto aplicativo de la ley.

La Ley de Partidos Políticos resucita una vieja cuestión: la de la democracia militante. Si bien el TEDH permite la persecución de fines ideológicos, es decir, de proyectos políticos no democráticos, en ningún caso la proscripción de este tipo de fines puede ser admitida en el supuesto español ${ }^{39}$. Por ello, el Tribunal Constitucional a la hora de determinar la finalidad legítima que encierra la disolución del partido establece que la misma "es la garantía de los procesos democráticos de participación política mediante la exclusión como partido de aquel ente asociativo que no se ajuste a las exigencias que respecto a la actividad, dimanan de la concepción constitucional de partido "40. El TEDH se adhiere a la tesis del Gobierno de España de que en ningún caso se pretende acabar con el pluralismo político en España, ya que en el territorio español coexisten pacíficamente diversos partidos políticos de ideología nacionalista e independentista que ejercen su actividad con total normalidad ${ }^{41}$. Con ello sanciona que el Estado español no ha operado una suerte de persecución ideológica de la «izquierda abertzale", y que no ha incurrido, por tanto, en un supuesto de democracia militante.

39 RODRÍGUEZ, A, "La declaración de inconstitucionalidad del partido...", "No es posible utilizar la convención como criterio hermenéutico para determinar el canon de constitucionalidad de la ley. Y ello afecta a las exigencias de la convención: no a la previsión de la ley pero sí al control ideológico como finalidad que persiga la restricción y a la necesidad en una sociedad democrática que tiene tintes también de democracia militante", op cit pág. 173. ALÁEZ CORRAL, B, "Libertad de expresión e ilegalización de partidos políticos", Repertorio Aranzadi del Tribunal Constitucional, Tomo III, sep-dic. 2002, pág. 2166.

40 La STC 48/2003, de 12 de marzo, en su FJ 7 niega que la Ley de Partidos sea un supuesto de democracia militante: «... en nuestro ordenamiento constitucional no tiene cabida un modelo de "democracia militante"... esto es, un modelo en el que se imponga, no ya el respeto, sino la adhesión positiva al ordenamiento y, en primer lugar, a la Constitución... Falta para ello el presupuesto inexcusable de la existencia de un núcleo normativo inaccesible a los procedimientos de reforma constitucional que, por su intangibilidad misma, pudiera erigirse en parámetro autónomo de corrección jurídica, de manera que la sola pretensión de afectarlo convirtiera en antijurídica la conducta que, sin embargo, se atuviera escrupulosamente a los procedimientos normativos... La Constitución española, a diferencia de la francesa o la alemana, no excluye de la posibilidad de reformar ninguno de sus preceptos ni somete el poder de revisión constitucional a más límites expresos que los estrictamente formales y de procedimiento. Ciertamente, nuestra Constitución también proclama principios, debidamente acogidos en su articulado, que dan fundamento y razón de ser a sus normas concretas. Son los principios constitucionales, algunos de los cuales se mencionan en los arts. 6 y 9 de la Ley impugnada. Principios todos que vinculan y obligan, como la Constitución entera, a los ciudadanos y a los poderes públicos (art. 9.1 CE), incluso cuando se postule su reforma o revisión y hasta tanto ésta no se verifique con éxito a través de los procedimientos establecido en su Título $\mathrm{X}$.

41 STEDH de 30 de junio de 2009, Casos Herri Batasuna y Batasuna, par. 62. 
El Tribunal de Estrasburgo estima que "la disolución perseguía varios de los fines legítimos enumerados en el artículo 11, particularmente el mantenimiento de la seguridad pública, la defensa del orden y la protección de los derechos y libertades de otros ${ }^{42}$.

\section{II.3. NECESIDAD EN UNA SOCIEDAD DEMOCRÁTICA Y PROPORCIONALIDAD DE LA MEDIDA}

Los demandantes entienden que la LO 6/2002, de Partidos Políticos viola asimismo el principio de proporcionalidad, pues la medida de disolución del partido es la única prevista legalmente para comportamientos que son muy diversos y que tienen distinta entidad. No se cumpliría así, en su opinión, la exigencia del TEDH de que la gravedad de la limitación sobre un derecho o libertad se debe adecuar a la trascendencia del comportamiento, de tal forma que la prohibición de un partido debe ser la última medida entre varias que se puedan tomar ${ }^{43}$.

El art. 11. 2 CEDH prescribe que la restricción del derecho de asociación política mediante la disolución del partido debe constituir una «medida necesaria en una sociedad democrática». Esta cláusula supone, en opinión de SAIZ ARNÁIZ, el verdadero punctum dolens del test de convencionalidad ${ }^{44}$.

En torno a este requerimiento han de realizarse algunas precisiones. Por un lado, aclarar el concepto de sociedad democrática al que se alude. La democracia se presenta como el eelemento fundamental del orden público europeo, ${ }^{45} \mathrm{y}$ constituye el único modelo compatible con el CEDH. El modelo de sociedad democrática que enuncia el Convenio es aquel que se caracteriza por ser una sociedad donde prime el pluralismo, la tolerancia y el espíritu de apertura, lo que conlleva que se asiente sobre los pilares del principio de preeminencia del Derecho, la libertad de expresión y la libertad del debate político $^{46}$. Este concepto de democracia va a implicar que los partidos políticos se conformen como elementos inescindibles de la misma; de ahí que el TEDH estime que "una de las características principales de la democracia reside en la

42 Idem par. 64.

43 Idem, par. 65.

44 SAIZ ARNÁIZ, A, “La disolución de partidos políticos...”, pág. 4. Vid en el mismo sentido pero para la aplicación del test de convencionalidad fuera del supuesto de los partidos políticos, FASSBENDER, B., "El principio de proporcionalidad en la jurisprudencia del Tribunal Europeo de Derechos Humanos" en Cuadernos de Derecho Público, No 5, Septiembre-Diciembre 1998, pág. 55.

45 Caso del Partido Comunista Unificado de Turquía y otros contra Turquía, de 30 de enero de 1998, par. 45.

46 GARCÍA ROCA, J. «El Preámbulo contexto hermenéutico del Convenio: un instrumento constitucional del orden público europeo", en el Vol. Col. "La Europa de los Derechos. El Convenio Europeo de Derechos Humanos", Centro de Estudios Políticos y Constitucionales, Madrid, 2009, págs. 46. GARCÍA SAN JOSÉ, D I, Los derechos y libertades..., op cit págs. 35 y 40. Vid la STEDH de 22 de octubre de 1981, Caso Dudgeon, pars. 48-61. 
posibilidad que ofrece de debatir mediante el diálogo y sin recurrir a la violencia las cuestiones planteadas por diferentes corrientes de opinión política, incluso las que puedan molestar o inquietar. La democracia se alimenta en efecto de la libertad de expresión. Es por lo que esta libertad... debe mantenerse... no sólo para las "informaciones" o "ideas" acogidas favorablemente o consideradas inofensivas o indiferentes, sino también para las que hieren, chocan o inquietan" ${ }^{47}$.

De otra parte, este tercer elemento, según la doctrina del TEDH, exige el cumplimiento de dos subcondiciones: que la injerencia en el derecho de asociación política haya de corresponderse con una "necesidad social imperiosa" y, además, que la restricción sea "proporcionada" a la finalidad legítima perseguida, por lo que uno de los rasgos característicos de esta jurisprudencia consistiría en incluir de facto aquí también el examen de la proporcionalidad en sentido estricto, es decir, el equilibrio entre los beneficios y los sacrificios que comporta la medida restrictiva ${ }^{48}$.

La subcondición de la "necesidad social imperiosa" se concreta en la existencia de un "potencial peligro" para el sistema democrático ${ }^{49}$. En fin, la exigencia de "necesidad en una sociedad democrática" supone que ha de existir una "necesidad social imperiosa" que justifique el límite al derecho fundamental, y que no es posible determinar en términos absolutos, sino que varía dependiendo de diversos factores: la naturaleza del derecho en cuestión, el interés público protegido y el grado en que éste requiera protección de forma razonable, proporcionada y de buena fe en las circunstancias del caso. En definitiva supone "concentrarse sobre el punto de saber si existen indicios que

47 Caso Handyside c. Reino Unido, 7 de diciembre de 1976, par. 49.

48 SAIZ ARNÁIZ, A, "La disolución de partidos políticos...”, op cit págs. 4 y 5. Para SAIZ estas dos subcondiciones se agrupan en el concepto general de proporcionalidad: "Creo que resulta adecuado a la propia jurisprudencia del TEDH hablar, pura y simplemente, de proporcionalidad (en sentido amplio, si se desea) como concepto que incluye tanto la necesidad social imperiosa de la restricción como su proporcionalidad "strictu sensum. ÁLVAREZ CONDE, E y CATALÀ i BAS, A, «La aplicación de la ley Orgánica de Partidos Políticos. Crónica inacabada de la ilegalización de Herri Batasuna, Batasuna y Euskal Herritarrok", op cit, pág. 31, GARCÍA SAN JOSÉ, D I, Los derechos y libertades..., op cit pág. 78. Así lo muestra el Tribunal en el Caso Partido de la Libertad y la Democracia par. 48; Partido Socialista par. 54 y Partido comunista par. 61.

49 BARRERO ORTEGA, A, "Reapertura del debate democracia abierta v. democracia militante en la jurisprudencia del Tribunal Europeo de Derechos Humanos", en MONTILLA MARTOS, J. A. La probibición de partidos, Ed. Universidad de Almería, 2004, analiza en las págs. 198 y ss la necesidad imperiosa donde afirma que se concreta en un riesgo real, cierto e inminente para la convivencia democrática (Sala, \&53, 77; Gran Sala, \&132, 102 en el caso de Refah Partisi). RODRÍGUEZ, A, "La declaración de inconstitucionalidad del partido...", pone de manifiesto que "el peligro no tiene por qué haberse materializado pero sí debe haber sido declarado por los tribunales nacionales y superar el control del propio TEDH así que el Estado no está obligado a esperar que el partido en cuestión llegue a poner en peligro realmente al sistema democrático, sino que puede actuar con carácter preventivo, siempre que el riesgo haya sido declarado por los tribunales nacionales y superado el control del propio TEDH (Partido del Bienestar, 101 y 102)", op cit pág.169. CATALÀ i BAS, A. H, "Libertad de expresión e información: la jurisprudencia del TEDH y su recepción por el Tribunal Constitucional: hacia un derecho europeo de los derechos humanos", op cit, págs. 287 y ss. 
muestren que el riesgo de daño a la democracia, siempre con la condición de que se acrediten, es suficiente y razonablemente próximo y sobre si los actos y discursos constituyen un todo que da una imagen de un modelo de sociedad concebido y propugnado por el partido, y que estaría en contradicción con la concepción de una "sociedad democrática" $"$.

Estas consideraciones conllevan que sean las autoridades nacionales las que evalúen, en primer término, la necesidad de la medida, para lo que cuentan con un "margen de apreciación". Se produce, pues, la conexión del principio de proporcionalidad con la doctrina del "margen de apreciación" "51. Si partimos del concepto de sociedad democrática que prescribe el Convenio, las restricciones en la libertad de asociación política deben ser excepcionales y estar suficientemente justificadas; de ahí que en la prohibición de partidos se reduzca el "margen de apreciación" de los Estados. Se trataría, pues, de una decisión estatal que debe superar un control europeo sumamente riguroso, un control que alcanza no sólo a la ley sino también a las decisiones judiciales que aplican la ley ${ }^{52}$.

Son muchos y muy variados los criterios que toma en cuenta el TEDH para apreciar la proporcionalidad de la disolución de un partido político. Así, puede valorar tanto su ideología — estatutos y programa- como sus actividades, tales como las declaraciones públicas de sus dirigentes, las decisiones de órganos jurisdiccionales internos que hayan conocido de acciones penales ejercitadas frente a miembros del partido en actividades conectadas con la vida política, la existencia de terrorismo en el país y la acreditada vinculación del partido con los grupos que lo practican ${ }^{53}$. De los parámetros utilizados es fácilmente deducible que Estrasburgo admite que se puede disolver un partido, no sólo en base a su comportamiento sino también con fundamento en su ideología antidemocrática. El TEDH introduce en la determinación de la ne-

50 STEDH de 30 de junio de 2009, Casos Batasuna y Herri Batasuna, par. 83.

51 Sobre el " margen de apreciación ", vid el amplio trabajo de KASTANAS, E, Unité et diversité: Notions autonomes et marge d'appréciation des Etats dans la jurisprudence de la Cour européenne des droits de l’homme, Bruxelles, 1996. GARCÍA ROCA, J. «La muy discrecional doctrina del margen de apreciación nacional según el Tribunal Europeo de Derechos Humanos: soberanía e integración" en Teoría y Realidad Constitucional, n. 20, 2007, págs. 117-143, y también de este autor "Soberanía estatal versus integración europea mediante unos derechos fundamentales comunes: ¿Cuál es el margen de apreciación nacional?, en Integración europea a través de los derechos fundamentales: de un sistema binario a otro integrado, García Roca, J y Fernández Sánchez, P.A. (coords), Centro de Estudios Políticos y Constitucionales, 2009, págs. 15-53.

52 «... las excepciones contempladas en el artículo 11 requieren una interpretación estricta, pues sólo razones convincentes e imperativas pueden justificar restricciones a la libertad de asociación. Para juzgar en estos casos... los Estados sólo disponen de un margen de apreciación reducido, completado con un control europeo riguroso tanto sobre la ley como sobre las decisiones que la aplican, incluidas las de los tribunales independientes..." (STEDH de 30 de junio de 2009, Casos Batasuna y Herri Batasuna par. 77).

53 Partido Comunista par. 59, Partido Socialista, par. 52 y Partido de la Libertad y la Democracia, par. 46, donde se reconoce que el TEDH «está dispuesto a tener en cuenta las circunstancias que rodean el caso sometido a su examen, en particular las dificultades unidas a la lucha contra el terrorismo". 
cesidad el elemento de la "democracia militante", pues parte de la premisa de que el único sistema compatible con el Convenio es la democracia, por lo que alos partidos pueden promover los cambios constitucionales que quieran siempre que cumplan dos condiciones: que los medios utilizados sean legales y democráticos, y que los cambios sean compatibles con los principios democráticos del Convenio ${ }^{54}$. En este marco, por tanto, no cabrían partidos políticos que inciten a la violencia o que tengan un proyecto político que no respete las reglas de la democracia o que persiga su destrucción y el desconocimiento de los derechos y libertades que la democracia reconoce ${ }^{55}$. Ahora bien, Rodríguez pone de manifiesto que, en términos generales, aunque el TEDH introduce mediante el control ideológico un supuesto de "democracia militante", esta medida es muy restrictiva y aquí el Estado tiene poco "margen de apreciación", "limitándose sólo a supuestos en los que puedan esgrimirse razones especialmente convincentes, y someterse en todo caso a una rigurosa supervisión por parte del TEDH, ${ }^{56}$. No debemos olvidar que el TEDH se autoimpone un control más riguroso en las injerencias estatales en las libertades de expresión, ideológica y de asociación — sobre todo políticasque el que lleva a cabo para otro tipo de actuaciones estatales, donde el Estado tiene mayor "margen de apreciación" en su actuación ${ }^{57}$.

No obstante, la variable del terrorismo es una circunstancia especialmente relevante en el juicio de necesidad-proporcionalidad del test de convencionalidad. A pesar de que el TEDH ha buscado un equilibrio entre el legítimo derecho de una sociedad democrática a protegerse frente a las actividades de organizaciones terroristas - Caso Zana c. Turquía de 25 de noviembre de 1997- y el obligado respeto por los Estados de las libertades y derechos, no cabe duda de que la derrota del terrorismo es «un interés público de primera magnitud en una sociedad democrática — Caso Betty Purcell y otros c. Irlanda de 16 de abril de 1991-, por lo que el terrorismo nos advierte Sáiz Arnáiz "podría ser uno de los ámbitos en los que... el TEDH podría reconocer un ampliado margen de apreciación a las autoridades nacionales al valorar el carácter necesario en una sociedad democrática de una medida severa en extremo como lo es, sin duda, la disolución de un partido político ${ }^{58}$. En este sentido, las Sentencias Klass, de 6 de septiembre de 1978 y Malone de 2 de agosto de 1984 afirman que los Estados democráticos tienen un derecho legítimo a adoptar las medidas necesarias para luchar contra el terrorismo,

54 STEH Partido del Bienestar, pars. 87 y 98.

55 STEDH de 30 de junio de 2009, Casos Batasuna y Herri Batasuna, par. 79.

56 RODRÍGUEZ, A, "La inconstitucionalidad...", op cit pág.169, vid también Caso Partido del Bienestar, par. 100

57 SAIZ ARNÁIZ, A, “La disolución de partidos políticos...”, op cit pág. 3. BILBAO UBILLOS, Juan María "Las libertades de reunión y asociación: algunas vacilaciones en una trayectoria de firme protección (art. 11 CEDH)", en La Europa de los Derechos. El Convenio Europeo de Derechos Humanos" (Vol. Col.) Ed. Centro de Estudios Políticos y Constitucionales, Madrid, 2009, págs. 672.

58 SAIZ ARNÁIZ, A, "La disolución de partidos...”, op cit pág. 5. GARCÍA SAN JOSÉ, D I, Los derechos y libertades... op. cit., pág. 69 
pero siempre desde el más estricto respeto al principio de legalidad. No cabe duda de que la circunstancia del terrorismo de ETA es determinante para que el Tribunal concluya que la ilegalización de Herri Batasuna y Batasuna se ajusta al principio de proporcionalidad exigido por el CEDH. Así, el Tribunal declara que al revisar la aplicación de la LO 6/2002 por el Tribunal Supremo español se pone fácilmente de manifiesto que la decisión judicial interna no se fundamenta en una mera falta de condena a la violencia terrorista de ETA por parte de los partidos encausados, sino que "presenta una enumeración de comportamientos que permitieron concluir que los partidos demandantes eran instrumentos de la estrategia terrorista de ETA, 59 . Incluso el TEDH clasifica estos hechos en dos grupos: aquellos que han favorecido un clima de confrontación social y aquellos otros que constituyen una actividad de apoyo implícito al terrorismo de ETA ${ }^{60}$. Es más, en su opinión, algunas de las actuaciones de los demandantes incluso se acercan aal apoyo explícito de la violencia y de ensalzamiento de personas verdaderamente ligadas al terrorismo" ${ }^{61}$.

Una de las cuestiones más interesantes que se abordan en la STEDH es la valoración que hace Estrasburgo del rechazo de los demandantes a condenar la violencia terrorista de ETA. Éste había sido uno de los temas más polémicos entre la doctrina española. Para una buena parte de autores la no condena o el silencio de Batasuna es, sin duda, un posicionamiento ideológico reprochable desde el punto de vista ético-moral, mas no puede ser calificado como un hecho ilícito, pues resulta una manifestación de las libertades ideológica y de expresión en su vertiente negativa ${ }^{62}$. La STC 5/2004, que resolvió el recurso de amparo planteado por Batasuna contra su ilegalización, parte del

59 STEDH de 30 de junio de 2009, Casos Batasuna y Herri Batasuna, par. 85. Estos hechos vienen relatados en el par. 34 de los Antecedentes del Procedimiento.

60 Este Tribunal recuerda en particular los eslóganes y expresiones pronunciadas durante la manifestación convocada por Batasuna en San Sebastián el 11 de agosto de 2002, a la cabeza de la cual se encontraban los dirigentes de este partido A.O., J.P. y J.A. En efecto, aparte de los eslóganes de apoyo a los prisioneros de la ETA, expresiones amenazante como " borroka da bide bakarra " (la lucha es la única vía), "zuek faxistak zarete terroristak" (vosotros, fascistas, sois los verdaderos terroristas) o "gora ETA militarra " (viva ETA militar) habían sido oídas. Por otra parte, este Tribunal debe hacer igualmente mención de la entrevista de un representante de Batasuna en el Parlamento vasco con el periódico Egunkaria el 23 de agosto de 2002, en la que el primero afirmó que " la ETA no está por la lucha armada por capricho, sino que es una organización que ve la necesidad de utilizar todos los instrumentos para hacer frente al Estado". Finalmente, el Tribunal llama la atención sobre la participación de un concejal de Batasuna en una manifestación de apoyo a la ETA, el reconocimiento de terroristas de la ETA como ciudadanos de honor en las localidades dirigidas por los demandantes y el hecho de que en el sitio Internet del segundo demandante figuraba el anagrama de "Gestoras Pro-Amnistia", organización declarada ilegal por el Juez Central de Instrucción $n^{\circ} 5$ de la Audiencia Nacional e inscrita en la lista europea de organizaciones terroristas (Posición común del Consejo de la Unión Europea 2001/931/PESC).

61 STEDH de 30 de junio de 2009, Casos Batasuna y Herri Batasuna, par. 86.

62 En este sentido se pronuncian especialmente PÉREZ ROYO, J en "El derecho de Batasuna a no condenar", El País, 20 de agosto de 2002 y CARRILLO, M., "La no condena del terrorismo y el Derecho", El País, 13 de agosto de 2002. 
presupuesto de que cuando se trata de un ciudadano el silencio o la negativa a condenar acciones terroristas es una manifestación protegida por las libertades ideológica y de expresión reconocidas constitucionalmente. Ahora bien, cuando es un partido político quien mantiene esa actitud y la mantiene en determinadas circunstancias, en concreto, en un contexto de violencia terrorista es claro que su actitud no es inocua, es decir, no supone un mero posicionamiento ideológico interno, sin trascendencia para el Derecho, sino que, por el contrario, se trata de una "manifestación tácita o implícita de un determinado posicionamiento frente al terror", que se utiliza para "complementar y justificar las acciones terroristas". En el contexto del terrorismo, pues, el silencio del partido revela una conducta con una "evidente densidad significativa", es una omisión concluyente, decisiva, que unida siempre a otros actos graves y reiterados realizados por el partido a lo largo de su trayectoria conllevan «un compromiso con el terror y contra la convivencia organizada de un Estado democrático". Se traduce, en suma, en una actitud de "apoyo político tácito" al terrorismo o de legitimación de las acciones terroristas que tiene un componente cierto de exculpación y minimización del significado del terrorismo, que forma parte de una estrategia de compromiso y justificación del terrorismo" "63. El standard del Tribunal Constitucional, en nuestra opinión, es lo suficientemente exigente a la hora de apreciar el alcance jurídico de la no condena de un partido político de las acciones terroristas. En primer término, porque se trata de una actitud que en un contexto de terrorismo supone un indicio de que se legitima la violencia terrorista y es una actitud, por otro lado, que en ningún caso supone de forma individualizada la disolución de un partido, sino que debe ir acompañada de otros hechos graves y reiterados.

El TEDH comparte la opinión de los tribunales españoles de que "la no condena de la violencia terrorista constituye una actitud de apoyo tácito al terrorismo y ello, en un contexto de terrorismo que existe desde hace treinta años y que es condenado por el resto de los partidos políticos en su conjunto ${ }^{64}$. No es la primera vez que el TEDH avala la utilización de este parámetro, pues «el comportamiento de los hombres públicos engloba de ordinario no sólo sus acciones o discursos, sino también, en ciertas circunstancias, sus omisiones o silencios, que pueden equivaler a tomas de posición y ser tan elocuentes como cualquier acción de apoyo expreso" (ver, mutatis mutandis, Caso Zdanoka c. Letonia $\$ \$ 123$ y 130, 2006). Pero es que además el Tribunal Europeo, al igual que el español, destaca que la disolución de los partidos no ha traído sólo causa de una mera negativa a condenar el terrorismo de ETA. En definitiva, la disolución judicial viene fundamentada en «una pluralidad de actos y de comportamientos, graves y reiterados, que permitían deducir un compromiso con el terror y contra la coexistencia organizada en el marco de un Estado democrático" ${ }^{65}$, por lo que "responde al motivo de disolución es-

63 STC 5/2004, FJ 18.

64 STEDH de 30 de junio de 2009, Casos Batasuna y Herri Batasuna, par. 88.

65 STEDH de 30 de junio de 2009, Casos Batasuna y Herri Batasuna, par. 88. 
tablecido en el artículo $9 \$ 2$ c) de la LOPP, a saber, completar y sostener políticamente la acción de organizaciones terroristas para alcanzar fines consistentes en perturbar el orden constitucional o alterar gravemente la paz pública $"$ "6 .

Llegados a este punto sólo cabe concluir que la disolución de estos partidos responde a una "necesidad social imperiosa", que se concreta en la existencia de un "potencial peligro" para el sistema democrático. Por consiguiente, el Tribunal "considera que los actos y discursos imputables a los partidos políticos demandantes constituyen un conjunto que arroja una imagen nítida de un modelo de sociedad concebido y propugnado por los partidos y que estaría en contradicción con el concepto de "sociedad democrática" (ver, a contrario, el asunto Partidul Comunistilor (Nepeceristi) y Ungureanu, ya citado). En conclusión, la sanción infligida a los demandantes por el Tribunal supremo, confirmada por el Tribunal constitucional, incluso dentro del reducido margen de apreciación de que disponen los Estado, puede razonablemente considerarse que responde a "una necesidad social imperiosa" ${ }^{67}$.

Es necesario, por último, abordar la exigencia de la otra subcondición: que la medida sea proporcionada a la finalidad perseguida. La determinación del TEDH es clara: "Así, teniendo en cuenta que los proyectos ya mencionados están en contradicción con la concepción de la "sociedad democrática" y comportan un fuerte peligro para la democracia española, la sanción infligida a los demandantes es proporcionada al fin legítimo perseguido en el sentido del artículo 11 \2 (Refah Partisi c. Turquia ya citada, \$\$ 133 y 134), ${ }^{68}$.

Debemos tener siempre presente que desde un punto de vista jurídico la ilegalización de partidos políticos supone una intervención drástica en un derecho fundamental, que resulta crucial para el propio sistema democrático. Y, en este sentido, el Tribunal Constitucional y el Tribunal Europeo de Derechos Humanos han partido de este presupuesto para enjuiciar qué medida limita el pluralismo político. En cierto modo, ésta es la paradoja que encierra una decisión legislativa de este tipo y de la ponderación de bienes que debe realizarse. El objetivo constitucional perseguido, a saber, la salvaguarda de la apertura del proceso político democrático y la defensa de las libertades y derechos fundamentales, no resulta indiferente a los propios derechos afecta$\operatorname{dos}^{69}$. De ahí que obligatoriamente deban extremarse las garantías jurisdic-

66 STEDH de 30 de junio de 2009, Casos Batasuna y Herri Batasuna, par. 87.

67 STEDH de 30 de junio de 2009, Casos Batasuna y Herri Batasuna, par. 91.

68 Idem par. 93. Y continúa: "Como resultado de un control riguroso de la presencia de razones convincentes e imperativas capaces de justificar la disolución de los partidos políticos demandantes, el Tribunal estima que esta ingerencia correspondía a una "necesidad social imperiosa" y era "proporcionada al fin propuesto". De ello resulta que la disolución puede ser considerada "necesaria en una sociedad democrática", en especial para el mantenimiento de la seguridad pública, y la defensa del orden y la protección de los derechos y libertades de otros, en el sentido del artículo $11 \$ 2 "$ (par. 94).

69 DENNINGER, "Democracia militante y defensa de la Constitución", en Manual de Derecho Constitucional, Benda, Maihofer, Vogel, Hesse y Heyde, Marcial, Pons, 2001, pág. 450. 
cionales, y de ahí, sin duda también, que el Tribunal Europeo y el Constitucional deban orientarse hacia un necesario equilibrio entre la protección del debate político y la pluralidad de opciones que está en la base de una sociedad democrática y el respeto de la legalidad y de las reglas del juego democrático. La STEDH de 30 de junio de 2009, Asuntos Herri Batasuna y Batasuna contra España, nos ha demostrado que es en la articulación concreta de la intervención, o en la interpretación que deba primar de ésta, donde una medida de esta trascendencia jurídico-política se juega su propia "legitimidad" desde un sistema democrático.

$$
\text { * * * }
$$

TrtLE: Political Parties Act and the European Conventional test: The dialogue between the Constitutional Court and European Court of Human Rights about the outlawing of Batasuna and Herri Batasuna.

ABSTRACT: The aim of this article is to examine the judgment of the European Court of Human Rights (ECHR) of 30 June 2009, on the Batasuna and Herri Batasuna Cases, which confirms the banning of these political parties. It addresses the importance, not so much legal but political of this judgment, and examines, in particular, the violations of the freedoms of association (article 11 ECHR) and expression (art. 10 ECHR) in order to evidence that the Law of Political Parties and their application by the Spanish courts to Herri Batasuna Batasuna overcomes, without problems the test of European conventionality. The European judgment points out that the Spanish system of dissolution of political parties gives more guarantees that the system of European Convention of Human Rights and that the context of terrorism is crucial when assessing the necessity and proportionality of a measure of this importance in a democratic society. The ruling of the ECHR is also a good example of dialogue between the ECHR and the Spanish Constitutional Court.

RESUMEN: El objetivo de este artículo es examinar la Sentencia del Tribunal Europeo de Derechos Humanos (TEDH) de 30 de junio de 2009, en los Asuntos Herri Batasuna y Batasuna, que confirma la ilegalización de estos partidos políticos. Aborda la trascendencia, no tanto jurídica, sino política de esta decisión, y examina, en concreto, las vulneraciones del derecho de asociación (art. 11 del CEDH) y la libertad de expresión (art. 10 CEDH) para mostrar cómo la Ley de Partidos Políticos y su aplicación por los tribunales españoles a Herri Batasuna y Batasuna supera, sin problemas, el test de convencionalidad europeo. La decisión europea pone de manifiesto cómo el sistema español de disolución de partidos es más garantista que el sistema del Convenio Europeo de Derechos Humanos y cómo el contexto del terrorismo es determinante a la hora de valorar la necesidad y proporcionalidad de una medida de esta trascendencia en una sociedad democrática. La Sentencia del TEDH es un buen ejemplo también del diálogo entre el TEDH y el Tribunal Constitucional español.

Key words: Democracy. Political pluralism. Dissolution of political parties. Freedom of association. Freedom of speech. Terrorism. Test of conventionality.

Palabras clave: Democracia. Pluralismo político. Disolución de partidos. Derecho de asociación. Libertad de expresión. Terrorismo. Test de convencionalidad. 